\title{
PERILAKU BIDAN DALAM KUNJUNGAN NEONATUS DI WILAYAH KERJA PUSKESMAS SABANG KECAMATAN BULAGI UTARA KABUPATEN BANGGAI KEPULAUAN
}

\author{
BAMBANG APOLINARIS BADALIA, RAMLI
}

\begin{abstract}
Abstrak
Kunjungan neonatus adalah pelayanan kesehatan kepada neonatus sedikitnya 3 kali yaitu kunjungan neonatus I (KN 1) pada 6 jam sampai dengan 48 jam setelah lahir, kunjungan neonatus II (KN 2) pada hari ke 3 sampai dengan hari ke 7 setelah kelahiran, dan kunjungan neonatus III (KN 3) pada hari ke 8-28 setelah kelahiran. Pelayanan kesehatan diberikan oleh bidan/dokter/perawat, yang dapat dilaksanakan di Puskesmas atau melalui kunjungan rumah. Penelitian ini bertujuan untuk memperoleh gambaran perilaku bidan dalam kunjungan neonatus di Wilayah Kerja Puskesmas Sabang Kecamatan Bulagi Utara Kabupaten Banggai Kepulauan Tahun 2015.

Jenis penelitian yang digunakan adalah penelitian kualitatif dengan pendekatan fenomenologi. Jumlah informan sebanyak 7 orang yang terdiri dari 6 orang informan biasa yaitu bidan di Wilayah Kerja Puskesmas Sabang, dan 1 orang informan kunci yaitu kepala Puskesmas Sabang. Metode sampling menggunakan Proporsive Sampling. Hasil penelitian diperoleh melalui wawancara mendalam dan observasi.

Hasil penelitian yang diperoleh tentang perilaku bidan dalam kunjungan neonatus di Wilayah Kerja Puskesmas Sabang yaitu bidan mengunjungi bayi umur neonatus disesuaikan dengan kondisi kesehatan bayi, bidan tidak mengunjungi bayi pada umur neonatus kalau tidak dipanggil untuk memeriksa bayi, dan bidan mengunjungi bayi pada umur neonatus kalau bidan yang menolong persalinan ibu bayi. Penyebab lain rendahnya cakupan kunjungan neonatus yaitu Jumlah bidan yang sedikit, adanya mitos yang berkembang di masyarakat bahwa bayi tidak boleh dibawa keluar rumah sebelum berumur 2 minggu, data tentang jumlah bayi yang dimiliki puskesmas tidak lengkap, dan tidak semua indikator pelayanan neonatus terpenuhi dikarenakan tidak adanya distibusi Vitamin K, pada sarana kesehatan di masing-masing desa.
\end{abstract}

\section{Kata Kunci : Kunjungan Neonatus \\ Daftar Pustaka : 20 (2003-2013)}




\section{PENDAHULUAN}

Banyak hal yang dapat dilakukan sebagai upaya untuk meningkatkan derajat kesehatan di Indonesia, salah satu hal yang mempunyai peran yang cukup penting dalam meningkatkan derajat kesehatan adalah menyelenggarakan pelayanan kesehatan secara umum. Pelayanan kesehatan masyarakat (Public Health Services) adalah sub sistem pelayanan kesehatan meliputi bidang peningkatan kesehatan (Promotif), pencegahan (Preventif), pengobatan (Kuratif), dan pemulihan (rehabilitatif) dengan sasaran masyarakat (Depkes RI, 2008).

Tujuan keempat dan kelima Millenium Development Goals (MDG's) pada tahun 2015, bagi Indonesia merupakan tantangan yang sangat berat walaupun berbagai upaya untuk memperbaiki derajat kesehatan ibu dan bayi baru lahir telah ditetapkan di Indonesia tetapi hasilnya belum memuaskan. Sesuai dengan kesepakatan global, Indonesia diminta untuk menurunkan angka kematian bayi menjadi 25 per 1000 kelahiran hidup pada tahun 2015.

Berdasarkan Undang-Undang Kesehatan Nomor 36 Tahun 2009 Pasal 3, tujuan pembangunan kesehatan adalah untuk meningkatkan kesadaran, kemauan dan kemampuan hidup sehat bagi setiap orang agar terwujud derajat kesehatan masyarakat yang setinggi-tingginya, sebagai investasi bagi pembangunan sumber daya manusia yang produktif secara sosial dan ekonomis.

Menurut H.L. Blum (1974) dalam Notoatmodjo (2003) bahwa status kesehatan masyarakat ditentukan oleh empat faktor yaitu perilaku, lingkungan, pelayanan kesehatan, dan herediter atau keturunan. Selanjutnya Green (1980) bahwa perilaku dilatarbelakangi oleh tiga faktor diantaranya adalah faktor predisposisi yaitu pengetahuan, sikap, kepercayaan, keyakinan, dan nilai-nilai, faktor pemungkin yaitu tersedia atau tidak tersedianya fasilitas-fasilitas atau sarana-sarana kesehatan, dan faktor pendorong atau penguat yaitu sikap dan perilaku petugas kesehatan atau petugas lain, yang merupakan kelompok referensi dari perilaku masyarakat (Notoatmodjo, 2010).

Indikator derajat kesehatan dan kesejahteraan masyarakat ditandai dengan jumlah kematian ibu, jumlah kematian bayi dan usia harapan hidup. Sampai saat ini, kematian bayi masih merupakan salah satu masalah prioritas bidang kesehatan ibu dan anak di Indonesia. Tingginya angka kematian bayi (AKB) serta lambatnya penurunan angka tersebut, menunjukan bahwa pelayanan kesehatan ibu dan anak sangat mendesak untuk ditingkatkan baik dari segi jangkauan maupun kualitas pelayanannya.

Angka kematian bayi (AKB) merupakan indikator yang sensitif terhadap ketersediaan, kualitas dan pemanfaatan pelayanan kesehatan terutama terhadap pelayanan perinatal. $\mathrm{AKB}$ di Indonesia masih terbilang tinggi yaitu 32/1000 kelahiran hidup, dimana jika dibandingkan dengan negara tetangga di bagian ASEAN seperti Philipina 26/1000 kelahiran hidup, Srilangka 13/1000 kelahiran hidup, dan Singapura 2/1000 kelahiran hidup (Kepmenkes RI, 2011).

Berdasarkan Survei Demografi dan Kesehatan Indonesia (SDKI), lebih dari tiga perempat dari semua kematian balita terjadi dalam tahun pertama kehidupan anak dan mayoritas kematian bayi terjadi pada periode neonatus (Kemenkes RI, 2012)

Berdasarkan Muslihatun (2010) dalam Darmawan (2011), dirumuskan bahwa bayi usia kurang dari 1 bulan merupakan golongan umur yang memiliki risiko gangguan kesehatan paling tinggi. Upaya kesehatan yang dapat dilakukan untuk mengurangi risiko tersebut antara lain dengan melakukan pertolongan kesehatan 


\section{Fakultas Kesehatan Masyarakat Universitas Tompotika Luwuk}

oleh tenaga kesehatan dan pelayanan kesehatan pada neonatus (0-28 hari) minimal dua kali yaitu satu kali pada umur 0-7 hari (Kunjungan neonatus 1) dan satu kali pada umur 8-28 hari (Kunjungan neonatus 2).

Kunjuangan neonatus adalah pelayanan kesehatan kepada neonatus sedikitnya 3 kali yaitu kunjungan neonatus I (KN 1) pada 6 jam sampai dengan 48 jam setelah lahir, kunjungan neonatus II ( $\mathrm{KN} 2$ ) pada hari ke 3 sampai dengan hari ke 7 setelah kelahiran, dan kunjuangan neonatus III (KN 3) pada hari ke 8-28 hari setelah kelahiran. Pelayanan kesehatan diberikan oleh bidan/dokter/perawat, yang dapat dilaksanakan di Puskesmas atau melalui kunjungan rumah (Panduan-Yankes-BBLBerbasis Perlindunagan Anak, 2010).

Penelitian telah menunjukan bahwa lebih dari $50 \%$ kematian bayi terjadi pada periode neonatus yaitu dalam bulan pertama kehidupan. Kurang baiknya penanganan bayi baru lahir yang lahir sehat akan menyebabkan kelainan-kelainan yang dapat mengakibatkan cacat seumur hidup, bahkan kematian. Misalnya, kurang baiknya pembersihan jalan nafas waktu lahir dapat menyebabkan masuknya cairan lambung ke dalam paru-paru yang mengakibatkan kesulitan bernafas, kekurangan zat asam, dan apabila hal ini berlangsung terlalau lama dapat mengakibatkan pendarahan otak, kerusakan otak dan kemudian keterlambatan tumbuh kembang. Dalam pelayanan kesehatan bayi baru lahir perilaku bidan sangatlah penting, seperti saat membersihkan jalan nafas, memotong dan merawat tali pusat, mempertahankan suhu tubuh bayi, identifikasi bayi, dan pencegahan infeksi (Prawirohardjo, 2009).

Dari hasil penelitian dan perhitungan yang dilakukan, ditemukan bahwa kematian neonatus di Indonesia pada tahun 2006-2010 sebesar 20 per 1000 kelahiran hidup. Angka ini jika diterjemahkan ke jumlah absolut berarti dari 4.608 .000 bayi yang lahir di Indonesia setiap tahunya, 100-454 bayi meninggal sebelum 1 bulan (Depkes RI, 2010).

Berdasarkan profil Dinas Kesehatan Kabupaten Banggai Kepulauan tahun 2013 dapat diketahui bahwa cakupan kunjungan neonatus di Wilayah Kerja Puskesmas Sabang Kecamatan Bulagi Utara mencapai 87, 4\% dan berdasarkan laporan tahunan Puskesmas Sabang Kecamatan Bulagi Utara Kabupaten Banggai Kepulauan tahun 2014, cakupan kunjungan neonatus di wilayah kerja Puskesmas Sabang, dapat dilihat pada tabel 1:

\section{Tabel 1 \\ Cakupan Kunjungan Neonatus Lengkap Berdasarkan Desa di Wilayah Kerja Puskesmas Sabang Kec. Bulagi Utara Kab. Banggai Kepulauan Tahun 2014}

\begin{tabular}{|c|c|c|c|c|}
\hline \multirow[t]{2}{*}{ No. } & \multirow[t]{2}{*}{ Desa } & \multirow{2}{*}{$\begin{array}{c}\text { Sasaran } \\
\text { Bayi }\end{array}$} & \multicolumn{2}{|c|}{$\begin{array}{c}\text { Kunjungan } \\
\text { Neonatus } \\
\text { Lengkap } \\
\text { (KN } \\
\text { Lengkap) }\end{array}$} \\
\hline & & & $\mathrm{n}$ & $\%$ \\
\hline 1 & Sabang & 28 & 15 & 9 \\
\hline 2 & Lukpanenteng & 24 & 1 & 1 \\
\hline 3 & Ombuli & 17 & 11 & 7 \\
\hline 4 & Koyobunga & 7 & 5 & 3 \\
\hline 5 & Sambulangan & 14 & 21 & 13 \\
\hline 6 & Bangunemo & 17 & 9 & 5 \\
\hline 7 & Bakalinga & 9 & 12 & 7 \\
\hline 8 & Mandok & 6 & 6 & 4 \\
\hline 9 & Bolubung & 8 & 15 & 9 \\
\hline 10 & Montop & 22 & - & - \\
\hline 11 & Paisuluno & 10 & 8 & 5 \\
\hline 12 & Minanga & 6 & - & - \\
\hline & Total & 168 & 103 & 61 \\
\hline
\end{tabular}

Sumber : Puskesmas Sabang, 2014.

Berdasarkan tabel 1, dapat dilihat bahwa cakupan kunjungan neonatus di wilayah kerja Puskesmas Sabang Kecamatan Bulagi 
Fakultas Kesehatan Masyarakat Universitas Tompotika Luwuk

Utara Kabupaten Banggai Kepulauan mengalami penurunan, yaitu dari $87,4 \%$ pada tahun 2013, turun menjadi $61 \%$ pada tahun 2014. Padahal, pada Rencana Pembangunan Jangka Menengah Daerah Provinsi Sulawesi Tengah tahun 2011-2016, cakupan pelayanan neonatus harus mencapai $88 \%$ pada tahun 2014, dan berdasarkan Standar Pelayanan Minimum (SPM) Kabupaten/Kota ditetapkan bahwa cakupan pelayanan neonatus harus mencapai $90 \%$ pada tahun 2015.

Berdasarkan uraian di atas, peneliti tertarik untuk melakukan penelitian tentang Perilaku Bidan dalam Kunjungan Neonatus di Wilayah Kerja Puskesmas Sabang Kecamatan Bulagi Utara Kabupaten Banggai Kepulauan Tahun 2015.

Berdasarkan latar belakang, maka peneliti ingin meneliti tentang Perilaku Bidan dalam Kunjungan Neonatus di Wilayah Kerja Puskesmas Sabang Kecamatan Bulagi Utara Kabupaten Banggai Kepulauan Tahun 2015.

\section{BAHAN DAN METODE}

\section{Jenis Penelitian}

Dalam penelitian ini, jenis penelitian yang digunakan adalah penelitian kualitatif dengan pendekatan fenomenologi.

\section{Lokasi dan Waktu Penelitian.}

Penelitian ini dilaksanakan di wilayah kerja Puskesmas Sabang Kecamatan Bulagi Utara Kabupaten Banggai Kepulauan, pada bulan Februari sampai bulan Maret 2015.

\section{Informan dan Informan Kunci}

1. Informan Informan dalam penelitian ini adalah bidan di Wilayah Kerja Puskesmas Sabang Kecamatan Bulagi Utara, dengan kriteria sebagai berikut :

a. Bersedia diwawancarai. b. Berdomisili tetap di lokasi penelitian.

2. Informan Kunci

Informan kunci adalah kepala puskesmas dan pemegang program KIA di Puskesmas Sabang Kecamatan Bulagi Utara Kabupaten Banggai Kepulauan.

3. Jumlah informan tidak ditentukan, tetapi dianggap telah memadai apabila telah sampai tingkat saturasi data yang artinya data yang diperoleh tidak memberikan tambahan informasi.

\section{Pengumpulan Data}

1. Data Primer

Data primer diperoleh dari hasil wawancara mendalam dengan menggunakan pedoman wawancara dan alat bantu seperti camera, hand phone dan catatan lapangan.

2. Data Sekunder

Data sekunder diperoleh dari laporan tahunan Dinas Kesehatan kabupaten Banggai Kepulauan dan laporan tahunan Puskesmas Sabang Kecamatan Bulagi Utara.

\section{Instrumen Penelitian}

Instrumen dalam penelitian ini adalah peneliti sendiri dengan dibantu oleh alat perekam wawancara dan pedoman wawancara.

\section{Pengolahan dan Analisis Data}

1. Cara Pengolahan Data

Pengolahan data dilakukan dengan beberapa tahap, yakni:

a. Analisis data dimulai dengan menelaah seluruh data yang tersedia dari hasil wawancara dan pengamatan.

b. Menyeleksi data, dimana peneliti memilih dan menyeleksi data-data yang diperoleh dari hasil penelitian yang kemudian akan digunakan dalam penganalisaan data. Hal ini 
Fakultas Kesehatan Masyarakat Universitas Tompotika Luwuk

digunakan untuk menghindari adanya penyimpangan data yang akan dianalisa.

c. Mengklarifikasikan data, dimana untuk memperoleh gambaran yang jelas dan kesimpulan yang tepat apabila datanya telah terkumpul.

d. Mereduksi data yang dilakukan dengan cara membuat resume dari pernyataan-pernyataan informan.

e. Pernyataan-pernyataan dari informan dibuat dalam matriks/tabel.

f. Data disajikan dalam bentuk narasi dan disertai dengan penjelasan.

2. Analisis Data

Analisis data dalam penelitian ini menggunakan teknik analisis data menurut Milles dan Huberman (1984) dalam Sugiyono (2012), yang diterapkan melalui tiga alur, yaitu :

a. Data Reduction

Data Reduction atau mereduksi data berarti menerangkan, memilah halhal pokok, memfokuskan pada halhal penting, dicari tema dan polanya.

b. Data Display

Tahapan selanjutnya setelah data direduksi, maka dilakukan display data atau penyajian data. Yang paling sering digunakan dalam menyajikan data pada penelitian kualitatif adalah teks yang bersifat naratif.

c. Conclusion

Tahapan melakukan pencarian makna dan kata kunci peristiwa yang bertujuan untuk membentuk pola dan alur sebab akibat dalam pembentukan konsep yang kemudian dijadikan proposisi.

\section{Uji Keabsahan Data}

Untuk menjamin keabsahan informasi yang telah didapatkan, maka diperlukan metode triangulasi data, yaitu :
1. Triangulasi sumber adalah membandingkan dan mengecek balik derajat kepercayaan suatu informasi yang diperoleh dari informan biasa dan informan kunci dalam penelitian.

2. Triangulasi Metode adalah metode yang dilakukan dengan melakukan wawancara dan observasi. Dimama pada saat wawancara, dilakukan pula observasi.

\section{HASIL PENELITIAN}

Penelitian dilaksanakan di Wilayah Kerja Puskesmas Sabang yang bertujuan untuk memperoleh informasi tentang bagaimana perilaku bidan dalam kunjungan neonatus dan penyebab rendahnya cakupan kunjungan neonatus di Wilayah Kerja Puskesmas Sabang. Pemilihan informan dilakukan dengan cara Purpossive Sampling, dengan pertimbangan sebagai berikut; informan bersedia diwawancarai, berdomisili tetap di wilayah kerja Puskesmas Sabang, dan penelitian dilakukan di desa/kelurahan yang memiliki bidan desa. Karakteristik informan dapat dilihat pada tabel 3 :

\section{Tabel 3}

Distribusi Informan Berdasarkan Umur, Tingkat Pendidikan, Pekerjaan

Di Wilayah Kerja Puskesmas Sabang Tahun 2015

\begin{tabular}{|r|r|r|r|r|r|}
\hline No. & $\begin{array}{r}\text { Nama } \\
\text { Informan }\end{array}$ & Umur & $\begin{array}{r}\text { Tingkat } \\
\text { Pendidikan }\end{array}$ & Pekerjaan & Keterangan \\
\hline 1. & FI & 38 & SPK & Bidan Desa & Informan \\
\hline 2. & UB & 36 & Amd. Keb & Bidan Desa & Informan \\
\hline 3. & NJ & 26 & Amd. Keb & Bidan Desa & Informan \\
\hline 4. & NP & 25 & Amd. Keb & Bidan Desa & Informan \\
\hline 5. & HL & 41 & SPK & Bidan Desa & Informan \\
\hline 6. & SH & 26 & Amd. Keb & $\begin{array}{r}\text { oordinator } \\
\text { Bidan }\end{array}$ & Informan \\
\hline 7. & CS & 51 & SPK & $\begin{array}{r}\text { Kepala } \\
\text { Puskesmas }\end{array}$ & $\begin{array}{r}\text { Informan } \\
\text { Kunci }\end{array}$ \\
\hline
\end{tabular}

Sumber Data : Primer 2015 
Fakultas Kesehatan Masyarakat Universitas Tompotika Luwuk

Hasil wawancara yang diperoleh dari informan tentang perilaku bidan dalam kunjungan neonatus dan penyebab rendahnya cakupan kunjungan neonatus di Wilayah Kerja Puskesmas Sabang, disajikan dalam bentuk narasi sebagai berikut:

1. Perilaku bidan dalam kunjungan neonatus, yaitu bidan mengunjungi bayi umur neonatus disesuaikan dengan kondisi kesehatan bayi, dimana jika tidak ada gangguan pada kesehatan bayi maka kunjungan neonatus tidak dilanjutkan. Jumlah kunjungan yang dilakukan bidan sebanyak 3 kali pada umur 0-7 hari dan atau sampai tali pusat bayi lepas. Hal ini dapat dilihat dari ungkapan informan berikut :

"Ya,

Kalu sa punya di sini sa pe pelayanan anu apa..3 kali pada umur 0-3 hari, setelah itu 3 hari sudah..so selesai kunjungan, nanti ada kendala baru kita kunjungi. (NP), (FI)

Kalu macam torang yang tolong, 1 minggu itu tiap hari, tergantung depe pusat dia keluar.” (UB)

2. Perilaku bidan dalam kunjungan neonatus, yaitu bidan tidak mengunjungi bayi pada umur neonatus kalau tidak dipanggil untuk memeriksa bayi. Hal ini dapat dilihat dari ungkapan informan berikut :

Kalu bukan torang yang tolong tidak..karna torang tidak dipangge, kalu dipangge jelas torang kunjungi." (UB), (NJ), (SH).

3. Selain itu, perilaku bidan dalam kunjungan neonatus, yaitu bidan mengunjungi bayi pada umur neonatus kalau bidan yang menolong persalinan ibu bayi. Hal ini dapat dilihat dari ungkapan informan berikut :

"Kalau lahir ditolong tenaga kesehatan, itu dimonitor terus." (UB), (NJ), (CS).
Penyebab rendahnya cakupan kunjungan neonatus di Wilayah Kerja Puskesmas Sabang selain dilihat dari perilaku bidan, dapat pula dilihat dari beberapa faktor lain, yaitu :

1. Kunjungan neonatus dikatakan lengkap jika semua indikator pelayananya terpenuhi. Namun di Wilayah Kerja Puskesmas Sabang sering terlambat dalam pengiriman Vitamin K ke masingmasing Poskesdes, sehingga banyak bayi yang tidak mendapatkan suntikan Vitamin K. Hal ini yang menyebabkan kunjungan neonatus lengkap di Wilayah Kerja Puskesmas Sabang rendah. Hal ini dapat dilihat dalam ungkapan informan berikut :

"Karna itu kan kunjungan neonatus, kalu torang ikut pelatihan baru-baru ini, semua target itu harus di penuhi, sedangkan target penyuntikan Vit. K, biasa depe Vit. $K$ itu terlambat datang dari Puskesmas. Jadi itu bayi setelah 1 minggu so tidak masuk itu kunjungan itu, karna kita baru mengikuti pelatihan harus masuk semua kunjungan itu. Jadi gagal, biar torang kunjungi tapi tidak masuk itu.” (UB)

2. Rendahnya cakupan kunjungan neonatus di Wilayah Kerja Puskesmas Sabang dikarenakan Jumlah bidan yang sedikit dimana hanya ada 6 orang bidan di Wilayah Kerja Puskesmas Sabang, sehingga dari 12 desa hanya ada 6 desa yang memiliki bidan. Hal ini dapat dilihat dari ungkapan informan berikut :

"Kan di sini ada 12 desa, sedangkan petugasnya hanya berapa, apalagi kalau bidan hanya di paisu luno, bolubung, mandok, bakalinga, sambulangan, sabang, jadi kendalanya juga itu." (HL)

3. Berdasarkan pernyataan Informan Kunci rendahnya cakupan kunjungan neonatus di Wilayah Kerja Puskesmas Sabang 
dikarenakan ibu bayi tidak memanggil bidan untuk memeriksakan bayinya karena bayinya sehat. Selain itu ada pula mitos yang berkembang di masyarakat, bahwa bayi tidak boleh dibawa keluar rumah sebelum berumur 2 minggu. Penyebab lainnya adalah karena ada bayi yang ibunya terdaftar tetapi bayinya tidak terdaftar karena ibunya bersalin di tempat lain, sehingga data yang ada tidak akurat dan selain itu rendahnya cakupan kunjungn neonats dikarenakan semua indikator pelayanan neonatus harus dipenuhi, jadi jika ada satu indikator yang tidak terpenuhi, maka kunjungan dianggap tidak lengkap. Hal ini dapat dilihat dari ungkapan informan berikut :

"Ya,

Kalau yang lahir ditolong tenaga kesehatan, itu dimonitor terus.

Ibu bayi tidak panggil bidan untuk periksakan bayinya karna dorang pikir tidak ada apa, sehat-sehat saja, jadi tidak perlu. Nanti so 1 bulan baru dorang bawa ke Posyandu. Dan petugas kesehatan tidak menunjungi karena sabantar dorang bilang tidak dipanggil. Baru di sini ada kepercayaan kalau belum 2 minggu belum bisa dibawa keluar rumah, mungkin mitos. Tidak tercatat karena melahirkan di puskesmas lain, jadi datanya itu misalnya tidak mungkin ada 7 ibu melahirkan kemudian bayinya tidak ada.

8 indikator pelayanan neonatus harus torang penuhi kalau tidak berarti tidak lengkap kunjungan neonatus. "(CS)

\section{PEMBAHASAN}

Berdasarkan hasil penelitian yang dilakukan di Wilayah Kerja Puskesmas Sabang, didapatkan hasil bahwa kunjungan neonatus yang dalam hal ini adalah kunjungan neonatus lengkap (KN L) belum berjalan dengan baik. Hal ini dapat lihat dari masih banyakya ibu nifas dan bayi umur 8-28 hari atau bayi yang telah lepas tali pusatnya, yang belum mendapatkan pelayananan neonatus lengkap.

Kunjungan neonatus di Wilayah Kerja Puskesmas Sabang belum berjalan dengan baik, disebabkan oleh berbagai faktor. Salah satu faktor yang menjadi penyebab utama rendahnya cakupan kunjungan neonatus yaitu perilaku bidan, dimana berdasarkan hasil wawancara dan observasi yang dilakukan peneliti terhadap informan dan ibu bayi yang ada di Wilayah Kerja Puskesmas Sabang, didapatkan hasil bahwa perilaku bidan dalam kunjungan neonatus di Wilayah Kerja Puskesmas Sabang adalah sebagai berikut :

1. Bidan mengunjungi bayi umur neonatus disesuaikan dengan kondisi kesehatan bayi, dimana jika tidak ada gangguan pada kesehatan bayi maka kunjungan neonatus tidak dilanjutkan.

Melihat masalah tersebut, dapat dikatakan bahwa pengetahuan bidan tentang pentingnya kunjungan neonatus masih kurang. Kunjungan neonatus tetap hurus dilaksanakan oleh bidan pada umur bayi 0-28 hari walaupun kondisi kesehatan ibu dan bayinya telah membaik, karena kunjungan neonatus harus dilaksanakan minimal 3 kali, yaitu 1 kali pada 6 jam sampai 48 jam setelah kelahiran (KN I), 1 kali pada hari ke 3 sampai hari ke 7 setelah kelahiran (KN II), dan 1 kali pada hari ke 8 sampai hari ke 28 setelah kelahiran (KN III), dimana dalam melakukan kunjungan neonatus banyak hal yang harus dilakukan oleh seorang tenaga kesehatan khususnya bidan, seperti melakukan identifikasi pada bayi, malakukan perawatan tali pusat dan perawatan mata, serta pemberian vitamin K. Pentingnya kunjungan neonatus oleh tenaga 
kesehatan pada ibu nifas dan bayi usia neonatus merupakan hal yang perlu diperhatikan oleh pemerintah dan tenga kesehatan khususnya yang bertempat di Wilayah Kerja Puskesmas Sabang, agar kunjungan neonatus lengkap di Wilayah Kerja Puskesmas Sabang dapat berjalan dengan baik.

2. Bidan tidak mengunjungi ibu nifas dan bayi umur neonatus kalau tidak dipanggil oleh keluarga atau ibu bayi untuk memeriksa kesehatan ibu dan bayinya.

Berdasarkan Prawirohardjo (2009), masa neonatus merupakan masa kritis dari kehidupan bayi, dimana dua pertiga kematian bayi terjadi dalam empat minggu setelah persalinan dan 60\% kematian bayi baru lahir terjadi dalam waktu 7 hari setelah lahir. Dengan pemantauan melekat dan asuhan pada ibu dan bayi masa nifas dapat mencegah beberapa kematian ini.

Melihat hal tersebut maka sangat dibutuhkan kesadaran tenaga kesehatan untuk melakukan kunjungan neonatus pada ibu nifas dan bayi umur neonatus. Namun yang terjadi di Wilayah Kerja Puskesmas Sabang, masih didapatkan masalah bahwa tenaga kesehatan khususnya bidan yang tidak mengunjungi ibu nifas dan bayi umur neonatus, kalau tidak dipanggil untuk memeriksakan ibu dan bayinya. Hal ini menggambarkan masih kurangnya kesadaran bidan tentang pentingnya melakukan kujungan neonatus pada ibu nifas dan bayi umur neonatus. Selain itu, berdasarkan wawancara yang dilakukan terhadap ibu bayi didapatkan bahwa kerap terjadi pula ibu dan atau keluarga bayi telah menghubungi tenaga kesehatan atau bidan untuk memeriksakan kesehatan ibu dan bayinya, namun tenaga kesehatan tersebut tidak datang mengunjungi ibu bayi dan bayinya, sehingga ibu dan bayinya tidak mendapatkan pelayanan neonatus.

3. Bidan mengunjungi bayi pada umur neonatus kalau bidan yang menolong saat persalinan ibu bayi.

Pelayanan kesehatan neonatus harus dimulai sebelum bayi dilahirkan, melalui pelayanan kesehatan yang diberikan kepada ibu hamil. Penelitian telah menunjukan bahwa lebih dari 50\% kematian bayi terjadi pada periode neonatus yaitu dalam bulan pertama kehidupan. Kurang baiknya penanganan bayi baru lahir yang lahir sehat akan menyebabkan kelainan-kelainan yang dapat mengakibatkan cacat seumur hidup, bahkan kematian. Misalnya, kurang baiknya pembersihan jalan nafas waktu lahir dapat menyebabkan masuknya cairan lambung ke dalam paru-paru yang mengakibatkan bayi kesulitan bernafas (Prawirohardjo, 2009).

Bidan sebagai tenaga yang profesional mempunyai tanggung jawab yang sangat besar dalam hal ini, seperti bermitra dengan perempuan dalam memberikan dukungan, asuhan dan nasehat yang diperlukan selama kehamilan, pada saat persalinan dan nifas, dan memfasilitasi kelahiran serta memberikan asuhan kepada bayi baru lahir dan anak. Namun berdasarkan penelitian yang dilakukan di Wilayah Kerja Puskesmas Sabang, masih ditemukan banyaknya ketidaksesuaian dengan hal tersebut, dimana masih banyak ditemukan bahwa bidan tidak mengunjungi ibu nifas dan bayi umur neonatus, kalau bukan bidan yang menolong persalinan ibu bayi. Ada banyak hal yang menjadi alasan bidan tidak mengunjungi ibu nifas dan bayi umur neonatus, diantaranya bidan tidak mengetahui adanya bayi ditempat bidan 
tersebut bertugas dikarenakan bayi lahir ditolong oleh dukun, sehingga keberadaan bayi baru diketahui setelah ibu bayi tersebut mengikuti kegiatan posyandu yang dilaksakan di desa. Hal tersebut menunjukan masih kurangnya pengetahuan dan kesadaran tenaga kesehatan khususnya bidan tentang pentingnya kunjungan neonatus, karena bidan sebagai tenaga yang profesional seharusnya telah mempunyai berbagai strategi agar hal-hal seperti itu tidak perlu terjadi.

Penyebab rendahnya cakupan kunjungan neonatus di Wilayah Kerja Puskesmas Sabang, selain dilihat dari perilaku bidan, dapat pula dilihat dari beberapa faktor lain, yaitu :

1. Jumlah bidan yang sedikit dimana hanya ada 6 orang bidan di Wilayah Kerja Puskesmas Sabang, sehingga dari 12 desa hanya ada 6 desa yang memiliki bidan, seperti Kelurahan Sabang, Desa Bakalinga, Desa Mandok, Desa Bolubung, Desa Paisu Luno, dan Desa Sambulangan. Hal ini tentunya sedikit menyulitkan bidan dan tenaga kesehatan lainnya dalam melakukan pelayanan kesehatan, khususnya dalam melakukan kunjungan neonatus dikarenakan jarak antar desa di Wilayah Kerja Puskesmas Sabang yang cukup berjauhan, seperti jarak antara Kelurahan Sabang dan Desa Ombuli yang berjarak $\quad \pm 7 \mathrm{~km}$.

2. Adanya mitos yang berkembang dimasyarakat bahwa bayi tidak boleh dibawa keluar rumah sebelum berumur 2 minggu dan atau sebelum dibawa ke Gereja, dan mitos ini telah ada di tengah masyarakat sejak dahulu kala, sehingga mitos ini mempengaruhi cakupan kunjungan neonatus di Wilayah Kerja Puskesmas Sabang.

3. Adanya bayi yang ibunya terdaftar tetapi bayinya tidak terdaftar karena ibunya bersalin di tempat lain, sehingga data yang ada tidak akurat. Misalnya di Desa Lukpanenteng yang jaraknya tidak jauh dari kecamatan buko. Ibu hamil di Desa Lukpanenteng yang terdaftar di Puskesmas Sabang kebanyakan melakukan persalinan pada tenaga kesehatan yang bertugas di Wilayah Kerja Puskesmas Buko, sehingga data tentang bayi tersebut tidak tercatat pada data di Puskesmas Sabang.

4. Kunjungan neonatus dikatakan lengkap jika semua indikator pelayananya terpenuhi. Namun di Wilayah Kerja Puskesmas Sabang sering terlambat dalam pengiriman Vitamin K ke masingmasing Poskesdes dimasing-masing desa, sehingga banyak bayi yang tidak mendapatkan suntikan Vitamin K. Hal ini yang menyebabkan kunjungan neonatus lengkap di Wilayah Kerja Puskesmas Sabang rendah.

Hasil penelitian tersebut jika dikaitkan dengan beberapa penelitian lain berkaitan dengan rendahnya cakupan kunjungan neonatus, terdapat banyak perbedaan, seperti penelitian yang dilakukan oleh Yuniar (2004) yang dikutip dalam Darmawan (2011), rendahnya cakupan kunjungan neonatus dipengaruhi oleh berbagai faktor seperti pendidikan ibu yang rendah, sikap ibu yang negatif seperti takut salah dalam melakukan perawatan tali pusat, kurangnya dukungan dari keluarga, pengetahuan ibu yang kurang dan status ekonomi yang masih rendah.

\section{KESIMPULAN}

Berdasarkan hasil penelitian dan pembahasan, dapat ditarik kesimpulan bahwa perilaku bidan dalam kunjungan neonatus dan penyebab rendahnya cakupan kunjungan neonatus di Wilayah Kerja Puskesmas Sabang, adalah sebagai berikut:

1. Perilaku bidan dalam kunjungan neonatus di Wilayah Kerja Puskesmas 
Fakultas Kesehatan Masyarakat Universitas Tompotika Luwuk

Sabang yaitu bidan mengunjungi bayi umur neonatus disesuaikan dengan kondisi kesehatan bayi, bidan tidak mengunjungi bayi pada umur neonatus kalau tidak dipanggil untuk memeriksa bayi, dan bidan mengunjungi bayi pada umur neonatus kalau bidan yang menolong saat persalinan ibu bayi.

2. Penyebab lain rendahnya cakupan kunjungan neonatus yaitu Jumlah bidan yang sedikit, adanya mitos yang berkembang di masyarakat bahwa bayi tidak boleh dibawa keluar rumah sebelum berumur 2 minggu, data tentang jumlah bayi yang dimiliki puskesmas tidak lengkap, dan tidak semua indikator pelayanan neonatus terpenuhi dikarenakan tidak adanya distibusi Vitamin K, pada sarana kesehatan di masing-masing desa.

\section{SARAN}

1. Bagi masyarakat, diharapkan untuk lebih berperan aktif dalam memeriksakan bayinya di usia neonatus dan atau menghubungi tenaga kesehatan untuk datang memeriksa kesehatan bayi.

2. Bagi tenaga kesehatan, diharapkan untuk lebih berperan aktif dalam melakukan pelayanan kesehatan bagi masyarakat, khususnya pelayanan kesehatan pada bayi dan ibunya terutama pada saat persalinan dan pada usia neonatus $0-28$ hari, misalnya dengan melakukan kemitraan dengan dukun dalam menolong persalinan dan kunjungan neonatus rutin pada usia neonatus.

3. Bagi pimpinan dan seluruh pejabat struktural dan fungsional di Puskesmas Sabang, untuk dapat melengkapi segala hal yang dibutuhkan dalam pelayanan kesehatan bagi masyarakat, agar pelayanan kesehatan di Wilayah Kerja Puskesmas Sabang dapat berjalan dengan baik.
4. Bagi Dinas Kesehatan Kabupaten Banggai Kepulauan, untuk lebih aktif melakukan pelatihan-pelatihan dan penyegaran-penyegaran kepada tenaga kesehatan yang ada di seluruh puskesmas di Kabupaten Banggai Kepulauan, agar tenaga kesehatan dapat melaksanakan tugasnya dengan baik dan bertanggungjawab.

5. Bagi pemerintah daerah baik di tingkat kecamatan maupun kabupaten, untuk dapat sama-sama meningkatkan mutu pelayanan kesehatan di Wilayah Kerja Puskesmas Sabang, khususnya dalam mengurangi angka kematian ibu dan anak.

\section{DAFTAR PUSTAKA}

Dahlan, 2012. Langkah-Langkah Membuat Proposal Penelitian Bidang Kedokteran dan Kesehatan, Sagung Seto, Jakarta.

Darmawan, dkk, 2011. Hubungan Pengetahuan Ibu dan Dukungan Suami dengan Kunjungan Neonatus 1 (KN 1) di Wilayah Kerja Puskesmas Pasirlangu Kabupaten Bandung Barat, Stikes Jendral A. Yani. Cimahi.

Departemen Kesehatan RI, 2008. Profil Kesehatan Indonesia. Jakarta

Departemen Kesehatan RI, 2010. Profil Kesehatan Indonesia. Jakarta

Dinkes Propinsi Sulteng, 2012. Profil Kesehatan Propinsi Sulawesi Tengah, Palu 
Jurnal KesMas Untika Vol. 7 Nomor 1 Juni 2016

ISSN. 2086-3772

Fakultas Kesehatan Masyarakat Universitas Tompotika Luwuk

Kepmenkes RI, 2010. Panduan Pelayanan

Kesehaan Bayi Baru Lahir

Berbasis Perlindungan Anak,

Direktorat Kesehatan Anak

Khusus.

Kepmenkes RI, 2011. Alokasi Aggaran

Dana Dekosentrasi dan Tugas Pembantuan

Pelaksanaan Program

Pembangunan Kesehatan di

Provinsi dan

Kabupaten/Kota, Nomor 152/MENKES/SK/I/2011.

Jakarta

Kepmenkes RI, 2012. Profil Kesehatan Indonesia. Jakarta

Meilani, dkk, 2009. Kebidanan Komunitas, Fitramaya, Yogjakarta.

Manuaba, dkk, 2006. Buku Ajar Patalogi Obstetri Untuk Mahasiswa Kebidanan, EGC, Jakarta.

Notoatmodjo, 2010. Ilmu Perilaku Kesehatan, Rineka Cipta. Jakarta

Notoatmodjo, 2003. Pendidikan Dan Perilaku Kesehatan, Rineka Cipta, Jakarta.

Prawirohardjo, 2009. Buku Acuan Nasional Pelayanan Kesehatan Maternal dan Neonatal, Tridasa Printer, Jakarta.

Prawirohardjo, 2011. Ilmu Kebidanan Sarwono Prawirohardjo, Tridasa Printer, Jakarta.
Ramli, 2013. Perilaku Ibu Hamil dalam Pemeriksaan Kehamilan di Kabupaten Banggai Kepulauan Sulawesi Tengah, Tesis, Universitas Hasanudin. Makassar

Saryono, 2011. Metode Penelitian Kualitatif dalam Bidang Kesehatan, Muha Medika, Yogjakarta.

Sugiyono, 2012. Memahami Penelitian Kualitatif, Alfabeta, Bandung.

Supartini, Y. 2004. Buku Ajar Konsep Dasar Keperawatan Anak, EGC, Jakarta

Tiwi, 2009. Bidan Sebagai Profesi, Http://the2w.blogspot.com/20 09, diakses pada tanggal 18 desember 2014. 